\title{
Revealing Ultrafast Two-Electron Transfer Over Tryptophan with Mass Spectrometry
}

Hongying Zhong*, Yinghua Qi, Ruowei Jiang\#, Weidan Li, Xiaojie Yang, Shanshan Jia

Laboratory of Mass Spectrometry, College of Chemistry, Central China Normal University, Wuhan, Hubei 430079, P. R. China

Key Laboratory of Pesticides and Chemical Biology, Ministry of Education, Wuhan, Hubei 430079, P. R. China

\# These authors contribute equally to this work

* To whom correspondence should be addressed. Email:

hyzhong@mail.ccnu.edu.cn 


\begin{abstract}
Electron transfer crucial to bioenergetics is ubiquitously present in biological systems but most of them escape from direct observations. By using tryptophan and its derivatives with 1- $\mathrm{CH}_{3}, 2-\mathrm{CH}_{3}, 5-\mathrm{CH}_{3}$ and 5-OH substitutions as model molecules, we have unambiguously demonstrated successive two-electron transfer to tryptophan as well as electronic and vibrational excited molecular dissociation with mass spectrometry. The ultra-short time delay between two electrons down to sub-attosecond over a distance less than $10 \AA$ was found to cause the strong coupling of electronic and vibrational excitations that was validated by the observation of radical-radical coupling. Intramolecular $\mathrm{H}$ migrations along with two-electron transfer was demonstrated with $\mathrm{H} / \mathrm{D}$ exchange and ${ }^{13} \mathrm{C}$ stable isotope labeling. This proposed technique allows us to observe the ultrafast electron transfer from tryptophan to the heme group in myoglobin proteins. It bridges electron transfer to energy transfer that has been revealed in FRET alone. $\mathrm{Fe}^{\mathrm{II}}$ (porph ${ }^{*}$ ) and $\mathrm{Fe}^{\mathrm{I}}\left(\right.$ porph $^{*}$ ) resulting from one- and two-electron transfer, respectively, have been unambiguously identified.
\end{abstract}

Keywords: Electron Transfer; H Migration; H/D Exchange; Stable Isotope Labeling; Mass Spectrometry 


\section{Introduction}

Ultrafast electron-transfer (ET) over tryptophan that often acts as a relay or an electron donor is crucial in biological energy flow. ${ }^{1-9}$ Understanding of electron transfer (ET) is of both practical importance and fundamental significance. Various transient spectroscopies have been established to investigate such processes in the optical domain, which provide time-resolved absorption band-difference spectra at selected pump-probe delays for the proof of reduced or oxidized species in response to electronic or vibrational excitations. ${ }^{10-15}$ Scanning tunneling microscope (STM) is an emerging technique that can mechanically manipulate individual atoms or molecules on a surface. ${ }^{16-18}$ It is an efficient tool to monitor vibrational excitations by the STM tip induced motions ${ }^{19,20}$ or electronic excitations by the electron current tunneling between STM tip and the surface. ${ }^{21-26}$ In STM technique, daughter species resulting from molecular dissociations are identified by the final destinations on the surface as well as the dependence of radial and angular distributions on the tunneling current. It remains very difficult to elucidate detailed structures of unknown species.

Mass spectrometry may open new perspectives for such studies. It provides direct measurement of charges and masses of ions for structural identification. The proposed strategy is based on the analysis of radical anions resulting from the transfer of electrons to neutral tryptophan molecules as well as fragment ions formed through electronic- or vibrational-excited bond cleavages. Electrons that impact with tryptophan were photoelectrons generated on crystalline facets of semiconductor titanium dioxide with the irradiation of the $3^{\text {rd }}$ harmonic of $\mathrm{Nd}^{3+}$ :YAG pulsed laser (355 nm, 3ns) in a static electric field. Because tryptophan does not have absorption at $355 \mathrm{~nm}$ as shown in Supplementary Fig. S1 (A). it has been considered that following molecular dissociations are caused by the impact of electrons, instead of photo ionization. In addition to extensively investigated one-electron transfer, the focus of this work is to look for the intermediate ion carrying with two negative charges that provides direct experimental evidences for the occurrence of successive two-electron transfer. It is aimed to disentangle different fragment ions that are 
generated by electronic excitation, vibrational excitation as well as the roles of ultra-short time delay between two electrons over a few $\AA$ distance in the coupling of electronic and vibrational excitations. Tryptophan derivatives with 1- $\mathrm{CH}_{3}, 2-\mathrm{CH}_{3}$, 5- $\mathrm{CH}_{3}$ and 5-OH substitution as well as ${ }^{13} \mathrm{C}$ stable isotope labeling were used for the validation of specific bond cleavages and intramolecular H-migration. Fig. 1 illustrates how the mass spectrometric analysis is set up. The (001) or (110) facets of rutile titanium dioxide crystal adsorbed with tryptophan and derivatives was placed in a static electric field between the sample plate and the aperture. Bias voltages referred as V0-V3 were applied to the sample plate, extraction plate, hexapole and aperture, respectively.

The proposed approach has been applied to investigate ultrafast electron transfer to the heme group in myoglobin proteins. We have unambiguously detected the Fe II (porph • - ) and Fe I (porph • - ) ions that were generated through the first and the second electron transfer, respectively. It is the first time to observe two-electron transfer to the heme group in myglobin proteins to our knowledge. This finding is in accordance with the results reported by Chergui by using 2D UV spectroscopy. ${ }^{27,28}$

\section{Experimental Method}

Mass spectrometric analysis. All reagents and apparatus were listed in Supplementary Notes S1. Orientation of tryptophan on crystalline facets of titanium dioxide and the transportation distances of electrons were theoretically computed and summarized in Supplementary Notes S2. Mass spectrometric experiments were performed on a Waters MALDI Synapt G2 HDMS (Milford, USA) mass spectrometer. Laser pulses of the mass spectrometer were derived from the $3^{\text {rd }}$ harmonic of $\mathrm{Nd}$ : YAG high repetition laser head $(355 \mathrm{~nm})$ that is equipped in the source chamber of the mass spectrometer. Laser pulse energy, pulse width and fire rate are $100 \mu \mathrm{J}, 3$ ns and $200 \mathrm{~Hz}$ respectively. In the low mass region less than $1000 \mathrm{Da}$, mass spectrometer was calibrated every day in the morning with a mixture of PEG or fatty acids containing C4:0, C6:0, C8:0, C10:0, C12:0, C14:0, C16:0, C18:0, C20:0 and C22:0 
for positive and negative ion mode, respectively. One of the reports is shown in Supplementary Notes S3. The mixture of PEG or fatty acids was also used as the lock mass for internal calibration to ensure mass accuracy during the whole data acquisition. In order to avoid contamination of samples by volatile fatty acids or PEG, two samples were analyzed in parallel of which one sample was used for calibration and the other one was used for mass spectrometric analysis. Voltages on the sample plate and the aperture were set as 87 volts and 107 volts (20 volts bias voltage) for routine analysis, respectively. Those voltages can be adjusted to set bias voltages as $0.2,4,10,20$ and 40 volts. Tryptophan and derivatives or ${ }^{13} \mathrm{C}$ labeled tryptophan was dissolved in a solution containing 50\% water and 50\% acetone (100 $\mathrm{mg} \bullet \mathrm{mL}^{-1}$ ) or their deuterated counterparts for regular analysis or for H/D exchange experiments. Before mass spectrometric analysis, the solution of tryptophan or derivatives was spotted onto the surfaces of semiconductor crystalline facets and air-dried. As for the formation of sodium adducts, the solution of sodium acetate $\left(0.01 \mathrm{mg} . \mathrm{mL}^{-1}\right)$ was mixed with that of tryptophan or derivatives at a ratio of $1: 1$ $(\mathrm{V} / \mathrm{V})$ before spotting on the sample plate. In electron scavenge experiments, 1-hexadecanol dissolved in a solution of acetone $(10 \mathrm{mg} / \mathrm{mL})$ was deposited on the surfaces for scavenges of electrons in order to validate the escape of electrons from semiconductor surfaces and the subsequent transfer to adsorbed tryptophan molecules. After 1-hexadecanol solution is air-dried, tryptophan solution was deposited on the top for subsequent mass spectrometric analysis. In order to demonstrate the intramolecular $\mathrm{H}$ migration, effects of ammonia and $\mathrm{NaOH}$ on fragmentations have also been examined. In this case, tryptophan was dissolved in a solution of ammonia $(0.1 \mathrm{M})$ or $\mathrm{NaOH}(0.1 \mathrm{M})$ for mass spectrometric analysis. Di-hydroxyl benzoic acid (DHB) was dissolved in a solution containing 50\% water and 50\% acetonitrile to reach a concentration of $1.5 \mathrm{~mol} / \mathrm{L}$. Myoglobin was dissolved in water and the concentration is $10 \mu \mathrm{g} / \mu \mathrm{L}$. For mass spectrometric analysis of myoglobin in the positive ion mode, the solution was mixed with equal volume of DHB for co-crystallization before spotting on the surface of titanium dioxide crystalline facets in order to protect the heme group from photo-induced degradation. The absorption 
spectrum of myoglobin is shown in Supplementary Fig. S1 B.

\section{Results and Discussion}

Mass spectrometric analysis of tryptophan and molecular dissociations. Under the irradiation of the $3 \mathrm{rd}$ harmonic $\mathrm{Nd}^{3+}$ :YAG $(355 \mathrm{~nm})$, mass spectra of tryptophan (molecular weight: $204 \mathrm{Da}$ ) adsorbed on (001) or (110) crystalline facets of titanium dioxide at different bias voltages are shown in Figure 2. Ions in mass spectra can be classified into five types: (1) The radical anion at $\mathrm{m} / \mathrm{z}, 204$ with the same mass as that of the neutral tryptophan; (2) The highest fragment ion at $\mathrm{m} / \mathrm{z}, 203$ at low bias voltages $(<20 \mathrm{~V})$; (3) Ions in the low mass region with $\mathrm{m} / \mathrm{z}$ value less than 203; (4) The highest fragment ion at $m / z, 116$ at high bias voltage $(\mathrm{V} \geqslant 20 \mathrm{~V})$; (5) Ions in the high mass region with $\mathrm{m} / \mathrm{z}$ value more than 204 at high bias voltages $(\geqslant 20 \mathrm{~V})$.

Ions generated on (001) facet and (110) facet are different and the significance test is shown in Supplementary Notes S4. At high bias voltages, distinct ions indicated with red squares in Fig. 2 include: (1) The one at $\mathrm{m} / z 116$ that has the highest relative intensity in (001) facet but not in (110) facet. (2) Those ions between $257 \mathrm{Da}$ and $375 \mathrm{Da}$ that are strong in (001) facet but weak in (110) facet. In order to investigate why different ions were generated on different crystalline facets, molecular orientations of tryptophan on (001) and (110) were computed and shown in Supplementary Fig. S2. Supplementary Fig. S3 shows the two charge-deficient atoms of tryptophan. It was found that distances from (001) and (110) facets to the two charge-deficient atoms of tryptophan are different. In the static electric field, the traveling time of electrons from the facets to those atoms are different. Among these, distances from (001) or (110) facets to the carbon atom of the carboxyl group are similar and are $2.774 \AA$ and $3.419 \AA$, in corresponding to traveling 105.8 attoseconds and 130.3 attoseconds at $20 \mathrm{~V}$ bias voltage, respectively. But distances from (001) or (110) facets to the carbon atom in the indole ring are distinctly different and are $2.797 \AA$ and $9.008 \AA$, in corresponding to traveling 106.6 attosecond and 343.4 attosecond, respectively. So the time delay between the successive two 
electrons that are transferred to tryptophan on (001) facet is only about 0.8 attosecond but 213 attoseconds on (110) facet as summarized in Supplementary Table S1. The closer distance from the (001) or (110) facet to the carboxyl carbon atom than that to the carbon atom in the indole ring maybe due to the formation of hydrogen bonds between the carboxyl groups and oxygen atoms on crystalline facets.

\section{Radical anions with odd-number electrons resulting from one-electron transfer.}

Detection of radical anions is the key to whether has electron transfer occurred. Fig. 3 (A) indicate that such a radical anion is expected to be the one at $m / z 204$ resulting from one-electron transfer to the most charge deficient carbon atom of the carboxyl group. Then the ion at $m / z 204$ (Expt: 204.0899, Obs: 204.0891) in Figure 2 that was detected in the negative ion mode with the same mass as that of the neutral molecule is the direct experimental evidence for the transfer of one electron. The ${ }^{13} \mathrm{C}$ and ${ }^{15} \mathrm{~N}$ isotopic contribution was examined on intensity ratios of the ion at $\mathrm{m} / \mathrm{z}$ 204 over that of the ion at $m / z$ 203. As shown in Supplementary Fig. S4 (A), observed intensity ratios are significantly higher than that of the ${ }^{13} \mathrm{C}$ and ${ }^{15} \mathrm{~N}$ isotopic contribution (red line) when bias voltages are less than 1 volt. These experimental results indicate that the ion at $m / z, 204$ is not due to ${ }^{13} \mathrm{C}$ and ${ }^{15} \mathrm{~N}$ isotopic contribution alone. It proofs the presence of radical anion carrying with an unpaired electron. DFT (Density Functional Theory) calculation reveals that the transfer of electron to neutral tryptophan is an exothermic process proceeding spontaneously. The exothermic capture of electrons can occur at very low bias voltages even down to 0.2 V. But those low-energy electrons are not able to cause extensive vibrational excitation. Therefore, the intact radical anion at $\mathrm{m} / \mathrm{z}, 204$ can be detected at low bias voltage. The abundance of such radical anions is dependent on the stability of acquired charges. Although increased bias voltages facilitate the transfer of electrons, correspondingly increased kinetic energies cause dissociations of these radical anions. Because of these two opposite effects, the abundance of the ion at $\mathrm{m} / \mathrm{z} 204$ does not change significantly with bias voltages on both (001) and (110) facets in Supplementary Fig. S4 (B). In order to further validate the photoelectrons 
on laser irradiated semiconductor facets as well as the subsequent transfer to adsorbed tryptophan molecules, 1-hexadecanol was deposited on the surfaces of semiconductor facets for scavenges of electrons. Supplementary Fig. S5 demonstrates the blockage of electron transfer from surfaces of the semiconductor to tryptophan that further proofs the occurrence of electron transfer. One-electron transfer was also observed on other tryptophan derivatives which are summarized in Supplementary Notes S5.

Electronic excitation and electron-directed homolytic bond cleavages. Radical anions resulting from one-electron transfer are very active. DFT calculations shown in Supplementary Fig. S6 indicate that several bonds are activated and bond lengths elongate upon the acquisition of an additional electron in the neutral molecule. In Figure 3 (A), the negative ion at $\mathrm{m} / z 203$ with 1.0086 Da mass shift away from the original radical anion at $\mathrm{m} / \mathrm{z} 204$ implicates the loss of a hydrogen atom (error: 0.0008 $\mathrm{Da}$ ). It results from the electron-directed homolytic cleavage of $\alpha$-positioned $\mathrm{O}-\mathrm{H}$ bond next to the original $\mathrm{C}$ radical center. Such cleavage is facilitated by the presence of hydrogen bonds between the $\mathrm{H}$ atom of $\mathrm{OH}$ group and the oxygen atom on crystalline facets, which weaken the $\mathrm{O}-\mathrm{H}$ bond. Although $\alpha$-positioned C-N bond has much lower bond energy $(308 \mathrm{KJ} / \mathrm{mol})$, the predicted ion at $\mathrm{m} / \mathrm{z} .188 .0711$ was not detected probably due to the absence of such a hydrogen bond. This experimental observation is supported by the theoretical modeling in Supplementary Fig.S7 that clearly displays the leaving of the $\mathrm{H}$ atom of $\mathrm{OH}$ group. At low bias voltages $(<20$ V), the dominance of the negative ion at $\mathrm{m} / \mathrm{z} 203$ in mass spectra implicates that the homolytic cleavage of $\mathrm{O}-\mathrm{H}$ bond is highly favored.

This proposed cleavage is validated by H/D exchange experiments in Figure 3 (B). Tryptophan has been dissolved in a solution containing acetone-d6 and deuterium oxide-d2 (50\% v/v) with continuous vortexing for 2 hours in order to achieve an efficient $\mathrm{H} / \mathrm{D}$ exchange of $\mathrm{N}-\mathrm{H}, \mathrm{O}-\mathrm{H}$ as well as $1 \mathrm{C}-\mathrm{H}$ and $2 \mathrm{C}-\mathrm{H}$ in the indole ring. In Figure 3 (B), three intense peaks at $m / z, 204,205$ and 206 represent three H/D exchangeable $\mathrm{H}$ atoms in the ion at $m / z$ 203. It means that two $\mathrm{N}-\mathrm{H}$ bonds and a 
$1 \mathrm{C}-\mathrm{H}$ bond remain on the negative ion at $\mathrm{m} / \mathrm{z} 203$. The absence of the ion resulting from $\mathrm{H} / \mathrm{D}$ exchange of $\mathrm{O}-\mathrm{H}$ bond further confirms the cleavage of $\mathrm{O}-\mathrm{H}$ bond. Because of the weak acidity of the $2 \mathrm{C}-\mathrm{H}$ in the indole ring, the peak at $\mathrm{m} / \mathrm{z}, 207$ resulting from the $\mathrm{H} / \mathrm{D}$ exchange of the hydrogen atom of $2 \mathrm{C}$ on the indole ring is very weak. In summary, the homolytic cleavage of $\mathrm{O}-\mathrm{H}$ bond from the radical anion carrying with odd-number electrons results in the formation of the negative ion at $\mathrm{m} / \mathrm{z}$ 203 carrying with even-number electrons. Five tryptophan derivatives have been analyzed with the same approach and similar fragment ions are summarized in Supplementary Notes S5 and Supplementary Table S2, which supports the generality of electronic excitation and electron-directed homolytic bond cleavages.

Electronic excitation and charge-directed heterolytic bond cleavages. Another remarkable fact read from mass spectra is the presence of ions in the low mass region less than $203 \mathrm{Da}$, of which intensities dramatically change with bias voltages. Figure 4 (A) shows that the intensity of the ion at $\mathrm{m} / \mathrm{z} .159$ decreases while that of the ion at $m / z 142$ increases with increased bias voltages on both (001) and (110) facets. Opposite trends indicate that these two ions are generated from different parent ions in consecutive steps. The $43.9917 \mathrm{Da}$ mass difference between the ion at $\mathrm{m} / \mathrm{z} 203$ and the ion at $m / z, 159$ represents the loss of a neutral $\mathrm{CO}_{2}$ (error: $0.0019 \mathrm{Da}$ ) molecule. It is a negative charge-directed heterolytic $\mathrm{C}-\mathrm{C}$ bond cleavage as shown in Figure 4 (B). Newly formed even-electron fragment ion undergoes further dissociations to generate the ion at $m / z$ 142. The mass shift of 17.0266 Da represents the loss of a neutral $\mathrm{NH}_{3}$ (error:0.0002 Da ) through heterolytic cleavages of $\mathrm{C}-\mathrm{N}$ and $\mathrm{C}-\mathrm{H}$ bonds in Figure 4 (B). H/D exchange experiments shown in Figure 4 (C) confirms that the ion at $\mathrm{m} / z, 159$ has four H/D exchangeable atoms and the ion at expected $\mathrm{m} / \mathrm{z} 142$ has only one H/D exchangeable atom.

It has also been noted that relative intensities of fragment ions at $\mathrm{m} / \mathrm{z} 159$ and 142 are independent on quantities of tryptophan as shown in Supplementary Fig. S8. If the dissociation reactions are considered as zero-order kinetics, then $\mathrm{k}_{1} \mathrm{t}-\mathrm{k}_{2} \mathrm{t}=\mathrm{k}_{2} \mathrm{t}$ (defining 
$\mathrm{k}_{1}$ and $\mathrm{k}_{2}$ as rate constants) at $10 \mathrm{~V}$ bias voltage can be inferred from Figure $4(\mathrm{~A})$. It was then concluded that $\mathrm{k}_{1}$ is about two times of $\mathrm{k}_{2}$ at $10 \mathrm{~V}$ bias voltage, which is in accordance with the fact that the $\mathrm{C}-\mathrm{N}(308 \mathrm{KJ} / \mathrm{mol})$ and $\mathrm{C}-\mathrm{H}(413 \mathrm{KJ} / \mathrm{mol})$ bond energies needed for bond cleavages to generate the ion at $\mathrm{m} / \mathrm{z}, 142$ are about two times of that C-C bond energy $(348 \mathrm{KJ} / \mathrm{mol})$ needed to generate the ion at $\mathrm{m} / \mathrm{z} 159$. Increased bias voltages result in increased molecular dissociation. Similar experimental results of tryptophan derivatives are summarized in Supplementary Notes S5 and Supplementary Table S2, which supports the generality of electronic excitation and negative charge-directed heterolytic bond cleavages.

In summary, detection of the radical anion is the direct experimental evidence for the occurrence of one-electron transfer. Electronic excitation causes the radical anion to undergo electron-directed homolytic bond cleavages and subsequent charge-directed heterolytic bond cleavages.

Ultrafast two-electron transfer along with intramolecular $\mathbf{H}$ migration. In Figure 2, much attention has been attracted to the ion at $\mathrm{m} / \mathrm{z} 116$ detected in the negative ion mode. The following summarizes how the ultra-short time delay between two electrons down to sub-attosecond over a distance less than $10 \AA$ leads to the strong coupling of electronic excitations with vibrational excitations, as well as the validation of radical-radical coupling reactions.

In-direct evidences for two-electron transfer. As we have just discussed, the radical anion at $m / z 204$ has a negative carboxyl group $\mathrm{COO}^{-}$with an unpaired electron on the carbon atom. While the carbon radical center initiates the homolytic cleavage of $\alpha$-positioned $\mathrm{O}-\mathrm{H}$ bond, the accurate mass shift $87.0319 \mathrm{Da}$ between the ion at $\mathrm{m} / \mathrm{z}$ 203 and the ion at $m / z 116$ implicates the loss of the side chain $\cdot \mathrm{CH}_{2} \mathrm{CHNH}_{2} \mathrm{COO}^{-}$and the homolytical cleavage of $\mathrm{C}-\mathrm{C}$ bond, left-behind a neutral radical containing the indole ring. ${ }^{13} \mathrm{C}$ labeled tryptophan was used to validate if indole ring is present in the ion at $m / z$ 116. In Figure 5 (A), the ion at $m / z 117$ just besides the ion at $m / z 116$ 
Da proofs the presence of the indole ring in the ion at $m / z$ 116. Detected negative ion at $m / z 116$ confirms the acquisition of an additional electron that is delocalized in the indole ring. In Figure 5 (B), the transfer of the second electron to the charge deficient carbon atom in the indole ring (indicated by an arrow) activates 1-positioned $\mathrm{N}-\mathrm{H}$ bond. As soon as the 1-positioned $\mathrm{N}-\mathrm{H}$ bond is cleaved, resulting $\mathrm{H}$ atom substitutes 3-positioned side chain through an intramolecular $\mathrm{H}$ migration and then a new $\mathrm{C}-\mathrm{H}$ bond can be formed. In order to validate the intramolecular $\mathrm{H}$ migration from 1-positioned $\mathrm{N}-\mathrm{H}$ bond of the indole ring instead of $\mathrm{O}-\mathrm{H}$ bond of the carboxyl group, different bases such as $\mathrm{NH}_{3}$ and $\mathrm{NaOH}$ have been used to react with tryptophan, which contains an acidic- $\mathrm{COOH}$ proton, a weakly acidic $\mathrm{N}-\mathrm{H}$ proton and a very weakly acidic $\mathrm{C}-\mathrm{H}$ proton in indole ring. Because of the weak basicity of $\mathrm{NH}_{3}$, it is only enough for the deprotonation of acidic $\mathrm{COOH}$ but not enough for the deprotonation of N-H proton in the indole ring. It was noted in Supplementary Fig. S9 (A) that the deprotonation of $\mathrm{COOH}$ proton is not able to eliminate the formation of the ion at $\mathrm{m} / \mathrm{z}$ 116. It means $\mathrm{COOH}$ proton is not involved in intramolecular $\mathrm{H}$ migration. On the contrary, the reaction of tryptophan with stronger base $\mathrm{NaOH}$ that can cause partial deprotonation of $\mathrm{N}-\mathrm{H}$ proton in indole ring results in the obvious depletion of the ion at $m / z$ 116. These experimental results indicate that 1-positioned $\mathrm{N}-\mathrm{H}$ proton does participate in the formation of the ion at $\mathrm{m} / \mathrm{z} 116$. Figure 5 (C) reveals two H/D exchangeable atoms in the ion at $\mathrm{m} / \mathrm{z} 116$ which also support the intramolecular $\mathrm{H}$ migration along with two-electron transfer. Further validation of intramolecular $\mathrm{H}$ migration was performed on 1-methyl-tryptophan in which 1-positioned $\mathrm{N}-\mathrm{H}$ is substituted with a $\mathrm{CH}_{3}$ group. Figure 5 (D) shows the mass spectra of tryptophan and 1-methyl-tryptophan on (001) facets at $10 \mathrm{~V}$ bias voltages. The predicted ion at $\mathrm{m} / z, 130$ generated through the intramolecular migration of $\mathrm{CH}_{3}$ was not observed, although the energy needed to break the $\mathrm{N}-\mathrm{C}$ bond $(308 \mathrm{KJ} / \mathrm{mol})$ is lower than that to break the $\mathrm{N}-\mathrm{H}$ bond $(391 \mathrm{KJ} / \mathrm{mol})$. It is implicated that the absence of the ion at $\mathrm{m} / \mathrm{z}, 130$ is due to the much difficult migration of $\cdot \mathrm{CH}_{3}$ than that of $\cdot \mathrm{H}$ atom. Only increased bias voltage more than $20 \mathrm{~V}$ facilitates the migration of $\mathrm{CH}_{3}$ group as shown in Supplementary Fig. S10. Other derivatives such as 
2-methyl-tryptophan, 5-methyl-tryptophan and 5-hydroxyl-tryptophan that contain 1-positioed N-H group all generate predicted ions through the intramolecular $\mathrm{H}$ migration as shown in Supplementary Fig. S11-S13. All these results firmly demonstrate the two-electron transfer along with intramolecular $\mathrm{H}$ migration.

Direct evidences for two-electron transfer. In addition to those circumstantial evidences that are inferred from fragment ions, the most solid experimental evidence for two-electron transfer is the detection of the intermediate ion carrying with two electrons. Because of high activities, such ion undergoes instant electron-initiated dissociations that cannot be observed in regular mass spectrometric analysis as shown in Figure 2. It was found herein that the formation of $\mathrm{Na}^{+}$adducts can facilitate the detection of the active intermediate ion. When sodium acetate was added to the solution of tryptophan, the negative ion at $m / z 225$ just next to the negative ion at $\mathrm{m} / \mathrm{z}$ 203 was clearly shown in zoomed mass spectrum of Figure 6 (A). The accurate mass convinces the addition of $\mathrm{Na}^{+}$ion (error: $0.0009 \mathrm{Da}$ ). Because the mass spectrum was acquired in the negative ion mode, detection of a negative ion with the addition of a positive sodium ion unambiguously identify the presence of two negative charges. The positive $\mathrm{Na}^{+}$ion neutralizes one of the negative charges and then the adduct ion carrying with only one net negative charge flies to the detector. Full mass spectra of tryptophan and derivatives on (001) and (110) facets at different bias voltages are shown in Supplementary Fig. S14-S18. And zoomed mass spectra of the sodium adducts were shown in Supplementary Fig. S19.

Experimental evidences for the neutralization of one negative charge of $\mathrm{COO}^{-}$group by the positively charged sodium ion is the formation of the ion at $\mathrm{m} / \mathrm{z}, 130$ that was observed at high bias voltages $(>20 \mathrm{~V})$ in Figure $6(\mathrm{~B})$. As we have discussed, when the first electron transfers to the carbon atom of the carboxyl group, one unpaired electron and one negative charge are left on the carbon atom and oxygen atom, respectively, as shown in Figure 3 (A). In the absence of $\mathrm{Na}^{+}$ion, the negative charge of $\mathrm{COO}^{-}$group initiates heterolytic $\mathrm{C}-\mathrm{C}$ bond cleavage that causes the loss of 
$\mathrm{CO}_{2}$ followed by the loss of $\mathrm{NH}_{3}$. When the negative charge is neutralized by the $\mathrm{Na}^{+}$ion, the unpaired electron-directed homolytic cleavage of $\alpha$-positioned $\mathrm{C}-\mathrm{C}$ bond along with the intramolecular $\mathrm{H}$ migration, competes with negative charge-directed heterolytic bond cleavages. Resultant ions generated by tryptophan and derivatives are shown in Figure 6 (B). As for 1-methyl-tryptophan, the predicted ion at $m / z, 142$ along with $-\mathrm{CH}_{3}$ migration was not observed until the bias voltage was increased to more than $30 \mathrm{~V}$. It has been repeatedly demonstrated that the migration of $-\mathrm{CH}_{3}$ group is more difficult than that of $\mathrm{H}$ atom.

In contrast to transient spectroscopic techniques that measure light absorbance or photoemission as a function of wavelength or the time delay between the pump and the probe, this work explores a new way to tackle with non-radiative electron transfer processes through the measurement of mass-to-charge $(\mathrm{m} / \mathrm{z})$ ratios of various ions. The first electron activates and ionizes the neutral molecule and the second electron functions as the probe to trace electron- or charge-initiated reactions. Figure 7 shows that intensities of the ion at $m / z 116$ change with bias voltages on both (001) and (110) facets. It was found that electrons with more than $20 \mathrm{eV}$ kinetic energies make distinguished performance. At $20 \mathrm{~V}$ bias voltage, 0.8 attosecond time delay of the second electron (on 001 facet) results in the strongest intensity of the ion at $\mathrm{m} / \mathrm{z}$ 116, which is much higher than that of 213 attosecond time delay (on 110 facet). In another words, the impact of successive two electrons with sub-attosecond time delay over distances less than $10 \AA$ causes extensive vibrational excitation along with intramolecular $\mathrm{H}$ migration and the formation of the ion at $m / z, 116$. With decreased bias voltages and then decreased kinetic energies of electrons, time delays make no obvious differences in intensities of the ion at $\mathrm{m} / \mathrm{z} 116$ on both (001) and (110) facets.

Vibrational excitation and radical-radical cross-coupling. A very unique finding in Figure 2 is the presence of a series of ions with $\mathrm{m} / \mathrm{z}$ values more than that of the molecular ion at $m / z, 204$ on (001) facet. It was shown that intensities of these ions dramatically increase with increased bias voltages $(>40 \mathrm{~V})$ on both (001) and (110) 
facets as shown in Figure 8 (A). Careful examination of these ions reveals intriguing radical-radical cross-coupling reactions. Among C-N (308 KJ/mol), C-C (348 $\mathrm{KJ} / \mathrm{mol})$, $\mathrm{O}-\mathrm{H}(459 \mathrm{KJ} / \mathrm{mol})$ and $\mathrm{C}-\mathrm{H}(413 \mathrm{KJ} / \mathrm{mol})$ bonds, $\mathrm{C}-\mathrm{N}$ bond and $\mathrm{C}-\mathrm{C}$ bond have relative low bond energy. The impact of electrons causes vibrational excitation of these two bonds and results in the formation of the radicals shown in Figure 8 (B) and (C). Cross-coupling of these radicals with the radical anion resulting from electronic excitation generates the negative ion at $\mathrm{m} / \mathrm{z}, 375,257$ and 300. In Figure 8 (D), it has been noted that the vibrational excitation maybe spontaneously impacts on multiple bonds. The intensity of such ion at $\mathrm{m} / \mathrm{z} 346$ increases with increased bias voltages because of the complement of kinetic energies needed for cleavages of multiple bonds under high bias voltages. Comparing Figure 8 with Figure 2, it was recognized that vibrational-excited multiple bond cleavages occur at high bias voltage $(>40 \mathrm{~V})$. Other tryptophan derivatives also show similar molecular dissociation (Supplementary Fig. S20-S23).

Figure 8 (E) shows an interesting ion at $\mathrm{m} / \mathrm{z} 167$ that is generated through the vibrational-excited $\mathrm{C}-\mathrm{N}$ bond cleavage followed by the migration of $\mathrm{NH}_{2}$ group and dehydrations. Because of high energies needed for such reactions, this ion was only observed at high bias voltages $(>20 \mathrm{~V})$. In contrast to those ions associated with one-electron transfer at low bias voltages less than $20 \mathrm{~V}$, Figure 8 (F) shows the ions at $m / z, 282,296$ and 308 that are produced from two-electron transfer along with $\mathrm{NH}_{2}$ migration at high bias voltages more than $20 \mathrm{~V}$.

In summary, the time delay between two electrons plays crucial roles in the coupling of electronic excitation with vibrational excitation. High bias voltage results in ultra-short time delay between the first- and the second-electron that is down to sub-attosecond for tryptophan molecules. The transfer of successive of two electrons to two charge deficient atoms within a distance less than $10 \AA$ leads to the extensive coupling of electronic excitations with vibrational excitations along with multiple bond cleavages and intramolecular migrations of $\mathrm{H}$ atoms or other functional 
groups such as $\mathrm{NH}_{2}$ group.

\section{Ultrafast two-electron transfer to the heme in myoglobin and perspectives.}

Currently, fluorescence resonance energy transfer (FRET) is a widely used technique for probing structural dynamics of proteins. It relies on the photo-excitation of a donor chromophore and the detection of changes in fluorescence signals that have been assumed due to the energy transfer alone. Among amino acid residues, tryptophan has been found in most proteins and has become as a local natural probe or spectroscopic ruler of protein structures and dynamics in fluorescence resonance energy transfer (FRET) technique. By using UV 2D spectroscopy, Chergui ${ }^{27,28}$ have demonstrated the parallel ultrafast one-electron transfer from tryptophan to the heme group in myoglobin.

With mass spectrometry, we found the ultrafast two-electron transfer to the heme group of myoglobin proteins. An interesting ion at $\mathrm{m} / \mathrm{z} 616$ appears in the mass spectrum of positive ion mode of myoglobin shown in Figure 9 (A). As we know, the molecular weight of Fe II (porph) is $616 \mathrm{Da}$. Because mass spectrometry detects mass-to-charge ratios of ions, the ion Fe II (porph) is expected to appear at $m / z 308$. Observation of the ion at $\mathrm{m} / \mathrm{z} 616$ Da unambiguously demonstrates the transfer of one electron to the heme group. The formation of Fe II (porph • - ) but not Fe I (porph) is determined by the relative energy of the iron $d_{x 2-y 2}$ orbitals and the porphyrin $e_{g}$ orbitals as reported by Chergui. ${ }^{28}$ Even more interesting ion is the one at $m / z 639$. Its accurate mass unambiguously indicates the addition of a $\mathrm{Na}^{+}$adduct ion which provides direct experimental evidences for two-electron transfer. These two electrons transfer to the porphyrin group and Fe II, resulting in the formation of $\mathrm{Fe}$ II (porph • - ) and Fe I (porph •-) $\mathrm{Na}^{+}$, respectively. Relative intensities of the ion at $m / z 639$ increase with increased bias voltages as shown in Figure 9 (B) and Supplementary Fig. S24. This is the first observation of two-electron transfer to the heme group in myoglobin to our knowledge. In the zoomed mass spectrum, the ion at $m / z, 638$ reveals the one electron transfer along with a loss of hydrogen atom 


\section{Conclusion}

This work demonstrates a mass spectrometric approach for the monitoring of ultrafast two-electron transfer processes. In contrast to spectroscopic approaches that use two laser pulses, two photoelectrons generated on surfaces of laser irradiated semiconductors have been used to probe the kinetics. It provides a new way to determine the dynamics of ultrafast electron transfer in the regime of attosecond through the mass spectrometric analysis of fragment ions on crystalline facets of semiconductors and the control of bias voltages, which provide driving forces for electron transfer. Highly active intermediate ions carrying with two electrons have been observed through the formation of $\mathrm{Na}^{+}$adducts. It has been unambiguously demonstrated that ultra-short time delay between two electrons down to sub-attosecond over a distance less than $10 \AA$ leads to the strong coupling of electronic excitations with vibrational excitations, which is further validated by radical-radical coupling reactions. By using this proposed technique, two-electron transfer to the heme group of myoglobin protein was found. $\mathrm{Fe}^{\mathrm{II}}$ (porph ${ }^{-}$) and $\mathrm{Fe}^{\mathrm{I}}$ (porph ') resulting from one- and two-electron transfer have been observed, respectively. The experimental results should also provide useful clues for understanding the function of Try-rich region of proteins.

\section{Supporting Information}

This material is available free of charge via the internet.

\section{Corresponding Author}

Email: hyzhong@mail.ccnu.edu.cn

\section{Author Contributions}

Hongying Zhong developed the concept, designed all experiments, analyzed all data and wrote the manuscript. Yinghua Qi performed all experiments of tryptophan derivatives, myoglobin and all theoretical computations with Material Studio and Gaussian software. Ruowei Jiang performed all experiments of tryptophan on mass spectrometry. Weidan Li performed ANOVA for significance testing of data sets. 
Xiaojie Yang has been involved in experiments on electron scavenge. Shanshan Jia has been involved in experiments.

\section{Notes of Conflict of Interest}

No

\section{Acknowledgment}

We thank Professor Yuan Ye of Huazhong University of Science and technology, Wuhan, P. R. China for his involvement in the statistical analysis. We greatly appreciate the support from National Natural Science Foundation of China (NSFC, 21575046, 81761128005 and 21834002), Research Funds of Central China Normal University from the Ministry of Education.

\section{References}

1. A. T. Yeh, C. V. Shank, J. K. McCusker, Ultrafast electron localization dynamics following photo-induced charge transfer, Science 2000, 289, 935-938.

2. C. Shih, A. K. Museth, M. Abrahamsson, A. M. Blanco-Rodriguez, A. J. Di Bilio, J. Sudhamsu, B. R. Crane, K. L. Ronayne, M. Towrie, A. Vlček Jr., J. H. Richards, J. R. Winkler, H. B. Gray, Tryptophan-accelerated electron flow through proteins, Science 2008, 320, 1760-1762.

3. K. Takematsu, H. R. Williamson, P. Nikolovski, J. T. Kaiser, Y. Sheng, P. Pospíšil, M. Towrie, J. Heyda, D. Hollas, S. Záliš, H. B. Gray, A. Vlček, J. R. Winkler, Two Tryptophans are better than one in accelerating electron flow through a protein, ACS Central Sci. 2019, 5, 192-200.

4. K. Takematsu, H. R. Williamson, P. Nikolovski, J. T. Kaiser, Y. Sheng, P. Pospíšil, M. Towrie, J. Heyda, D. Hollas, S. Záliš, H. B. Gray, A. Vlček, J. R. Winkler, Two Tryptophans are better than one in accelerating electron flow through a protein, ACS Central Sci. 2019, 5, 192-200.

5. M. Deloe, S. A. Archer, T. Keane, A. J. H. M. Meijer, I. V. Sazapovich, G. M. 
Greetham, M. Towrie, J. A. Weistein, Directing the path of light-induced electron transfer at a molecular fork using vibrational excitation, Nat. Chem. 2017, 9, 1099-1104.

6. M. Byrdin, A. P. M. Eker, M. H. Vos, K. Brettel, Dissection of the triple tryptophan electron transfer chain in Escherichia coli DNA photolyase: Trp382 is the primary donor in photo activation, Proc. Natl. Acad. Sci. 2003, 100, 8676-8681.

7. A. Vicek, Jr, H. Kvapilova, M. Towrie, S. Zalis, Electron-transfer acceleration investigated by time-resolved infrared spectroscopy, Acc. Chem. Res. 2015, 48, 868-876.

8. R. Roy, S. Hohng, T. Ha, A practical guide to single-molecule FRET, Nat. Methods 2008, 5, 507-516.

9. K. G. Andersen, A. Rambaut, W. I. Lipkin, E. C. Holmes, R. F. Garry, The proximal origin of SARS-CoV-2, Nat. Med. 2020, https://doi.org/10.1038/s41591-020-0820-9

10. A. L. Cavalieri, N. Müller, Th. Uphues, V. S. Yakovlev, A. Baltuška, B. Horvath, B. Schmidt, L. Blümel, R. Holzwarth, S. Hendel, M. Drescher, U. Kleineberg, P. M. Echenique, R. Kienberger, F. Krausz, U. Heinzmann, Attosecond spectroscopy in condensed matter, Nature 2007, 449, 1029-1032.

11. J. P. Hall, F. E. Poynton, P. M. Keane, S. P. Gurung, J. A. Brazier, D. J. Cardin, G. Winter, T. Gunnlaugsson, I. V. Sazanovich, M. Towrie, C. J. Cardin, J. M. Kelly, S. J. Quinn, Monitoring one-electron photo-oxidation of guanine in DNA crystals using ultrafast infrared spectroscopy, Nat. Chem. 2015, 7, 961-967.

12. A. Kafizas, X. Wang, S. R. Pendlebury, P. Barnes, M. Ling, C. Sotelo-Vazquez, R. Quesada-Cabrera, C. Li, I. P. Parkin, J. R. Durrant, Where do photogenerated holes go in anatase:rutile TiO2? A transient absorption spectroscopy study of charge transfer and lifetime, J. Phys. Chem. A 2016, 120, 715-723.

13. S. Ardo, Y. Sun, A. Staniszewski, F. N. Castellano, G. J. Meyer, Stark effects afterexcited-state interfacial electron transferat sensitized $\mathrm{TiO} 2$ nanocrystallites. $J$. Am. Chem. Soc. 2010, 132, 6696-6709. 
14. T. Tachikawa, N. Wang, S. Yamashita, S. C. Cui, T. Majima, Design of a highly sensitive fluorescent probe for interfacial electron transfer on a $\mathrm{TiO}_{2}$ surface, Angew. Chem. Int. Ed. 2010, 49, 8593-8597.

15. K. Hu, K. C. D. Robson, P. G. Johansson, C. P. Berlinguette, G. J. Meyer, Intramolecular hole transferatsensitized $\mathrm{TiO} 2$ interfaces. J. Am. Chem. Soc.2012, $134,8352-8355$.

16. D. M. Eigler, E. K. Schweizer, Positioning single atoms with a scanning tunnelling microscope. Nature 1990, 344, 524-526.

17. L. Bartels, G. Meyer, K. H. Rieder, Basic steps of lateral manipulation of single atoms and diatomic clusters with a scanning tunneling microscope tip. Phys. Rev. Lett. 1997, 79, 697-700.

18. T. Komeda, Y. Kim, M. Kawai, B. N. J. Persson, H. Ueba, H, Lateral hopping of molecules induced by excitation of internal vibration mode. Science 2002, 295, 2055-2058.

19. J. 1. Pascual, N. Lorente, Z. Song, H. Conrad, H. P. Rust, Selectivity in vibrationally mediated single-molecule chemistry. Nature 2003, 423, 525-528.

20. T. W. Fishlock, A. Oral, R. G. Egdell, J. B. Pethica, Manipulation of atoms across a surfaceat room temperature. Nature 404, 743-745 (2000).

21. G. P. Salam, M. Persson, R. E. Palmer, Possibility of coherent multiple excitation in atom transfer with a scanning tunneling microscope. Phys. Rev. B 1994, 49, 10655-10662.

22. B. C. Stipe, M. A. Rezaei, W. Ho, S. Gao, M. Persson, B. I. Lundqvist, Single-molecule dissociation by tunneling electrons. Phys. Rev. Lett. 1997, 78, $4410-4413$.

23. S. W. Hla, L. Bartels, G. Meyer, K. H. Rieder, Inducing all steps of a chemical reaction with the scanning tunneling microscope tip: Towards single molecule engineering. Phys. Rev. Lett. 2000, 85, 2777-2780.

24. J. Lee, D. C. Sorescu, X. Deng, Electron-induced dissociation of $\mathrm{CO}_{2}$ on $\mathrm{TiO}_{2}(110)$, J. Am. Chem. Soc. 2011, 133, 10066-10069.

25. P. A. Sloan, R. E. Palmer, Two-electron dissociation of single molecules by 
atomic manipulation at room temperature, Nature 2005, 434, 367-371.

26. T. L. Cocker, V. Jelic, M. Gupta, S. J. Molesky, J. A. Burgess, G. D. L. Reyes, L. V. Titova, Y. Y. Tsui, M. R. Freeman, F. A. Hegmann, An ultrafast terahertz scanning tunneling microscope, Nat. Photon. 2013, 7, 620-625.

27. C. Consani, G. Aubock, F. V. Mourik, M. Chergui, Ultrafast tryptophan-to-heme electron transfer in myoglobins revealed by UV 2D spectroscopy, Science 2013, $339,1586-1589$.

28. R. Monni, A. A. Haddad, F. V. Mourik, G. Auböck, M. Chergui, Tryptophan-to-heme electron transfer in ferrous myoglobins, Proc. Natl. Acad. Sci. 2015, 112, 5602-5606. 


\section{Figure Legend}

Figure 1. A mass spectrometric strategy for the monitoring of two-electron transfer.

Figure 2. Mass spectra of tryptophan molecules adsorbed on (001) facet (A) or (110) facet (B) of rutile titanium dioxide at different bias voltages.

Figure 3. One-electron transfer and electron-directed homolytic bond cleavage. (A) Generation of ions at $\mathrm{m} / z 203$ and 188. (B) Validation of the cleavage of $\mathrm{O}-\mathrm{H}$ bond by $\mathrm{H} / \mathrm{D}$ exchange experiments.

Figure 4. Charge-directed heterolytic bond cleavages. (A) Dependence on bias voltages. (B) Neutral losses of $\mathrm{CO}_{2}$ and $\mathrm{NH}_{3}$. (C) Validation of bond cleavages by $\mathrm{H} / \mathrm{D}$ exchange.

Figure 5. Two-electron transfer along with intramolecular $\mathrm{H}$ migration. (A) Mass spectrum of ${ }^{13} \mathrm{C}$ labeled and non-labled tryptophan. (B) Formation of the ion at $m / z$ 116. (C) Validation of $\mathrm{N}-\mathrm{H}$ and $\mathrm{C}-\mathrm{H}$ bonds with $\mathrm{H} / \mathrm{D}$ exchange. (D) Mass spectra of tryptophan and 1-methyl-tryptophan on (001) facet of rutile titanium dioxide at $10 \mathrm{~V}$ bias voltage.

Figure 6. Direct evidence of two-electron transfer. (A) Zoomed mass spectra of non-adducted and $\mathrm{Na}^{+}$-adducted tryptophan derivatives. (B) Carbon radical center-initiated homolytic cleavages of $\alpha$-positioned C-C bond along with intramolecular $\mathrm{H}$ migration.

Figure 7. Dependence of intensities of the ion at $\mathrm{m} / \mathrm{z} 116$ on time delays between two electrons and bias voltages. 
Figure 8. Vibrational excited bond cleavages and radical-radical coupling. (A) Mass spectra of tryptophan on (001) and (110) facets of rutile titanium dioxide at $40 \mathrm{~V}$ bias voltage. (B) Vibrational excitation of $\mathrm{C}-\mathrm{N}$ bond. (C) Vibration excitation of C-C bond. (D) Spontaneous vibrational excitation of O-H, C-C, $\mathrm{C}-\mathrm{H}$ and $\mathrm{C}-\mathrm{N}$ multiple bonds. (E) Vibrational excitation of $\mathrm{C}-\mathrm{N}$ bond along with intramolecular $\mathrm{NH}_{2}$ migration and dehydrations. (F) Radical-radical coupling along with intramolecular $\mathrm{NH}_{2}$ migration.

Figure 9. Ultrafast two-electron transfer to the heme group in myoglobin proteins. (A) Mass spectrum of myoglobin in the positive ion mode. (B) Dependence of relative intensities of the ion at $m / z 639$ on bias voltages. 


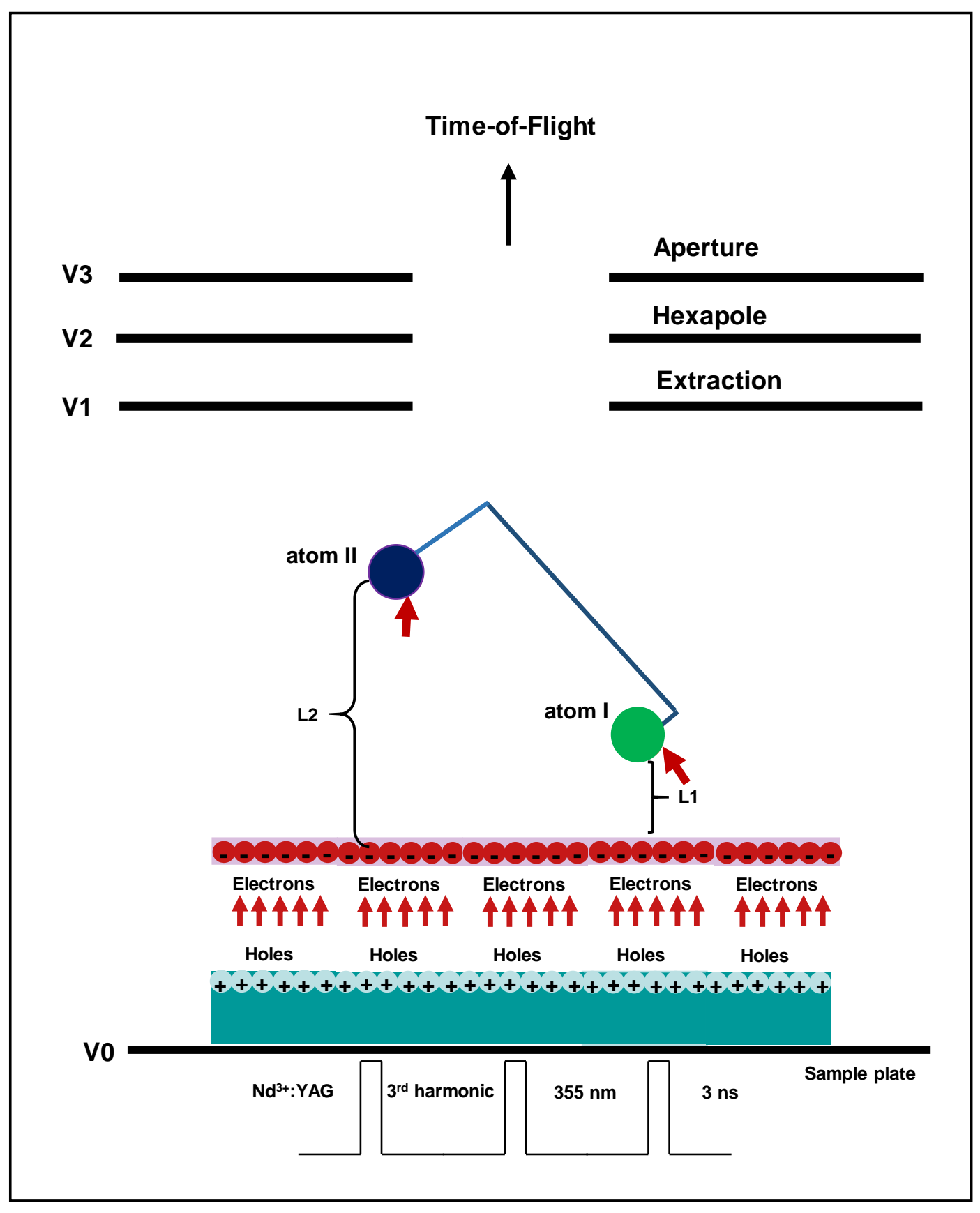

Figure 1 


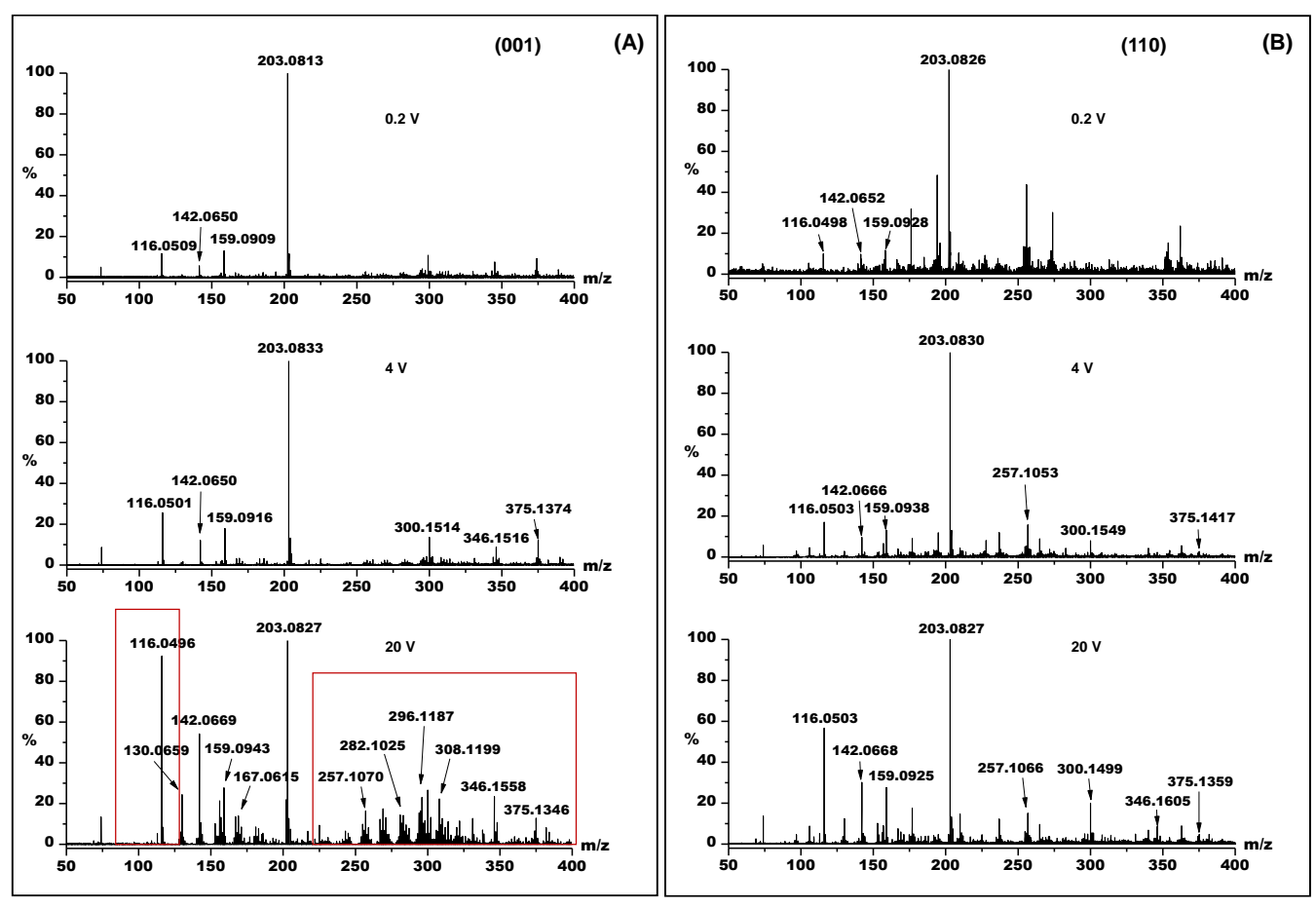

Figure 2 


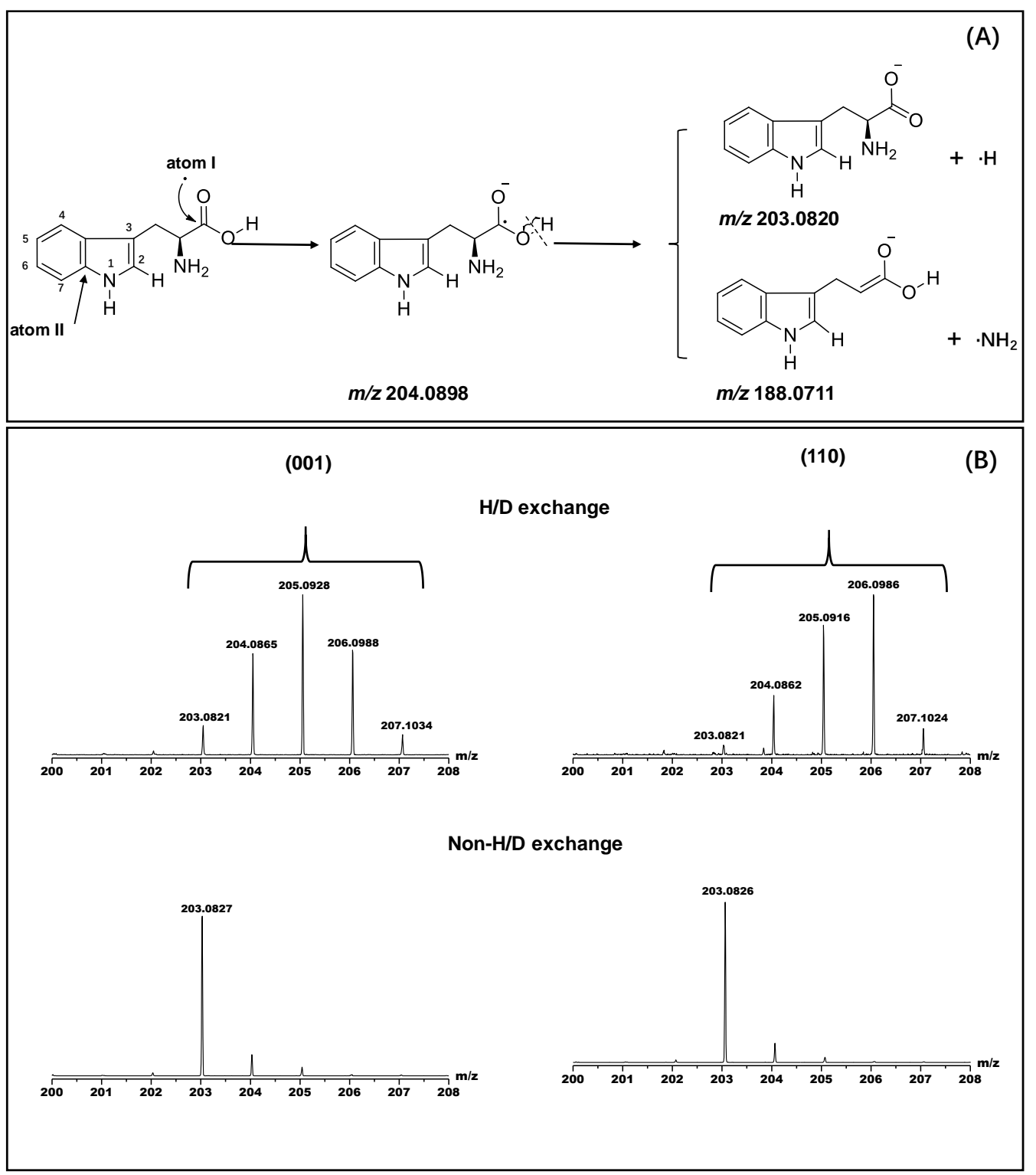

Figure 3 

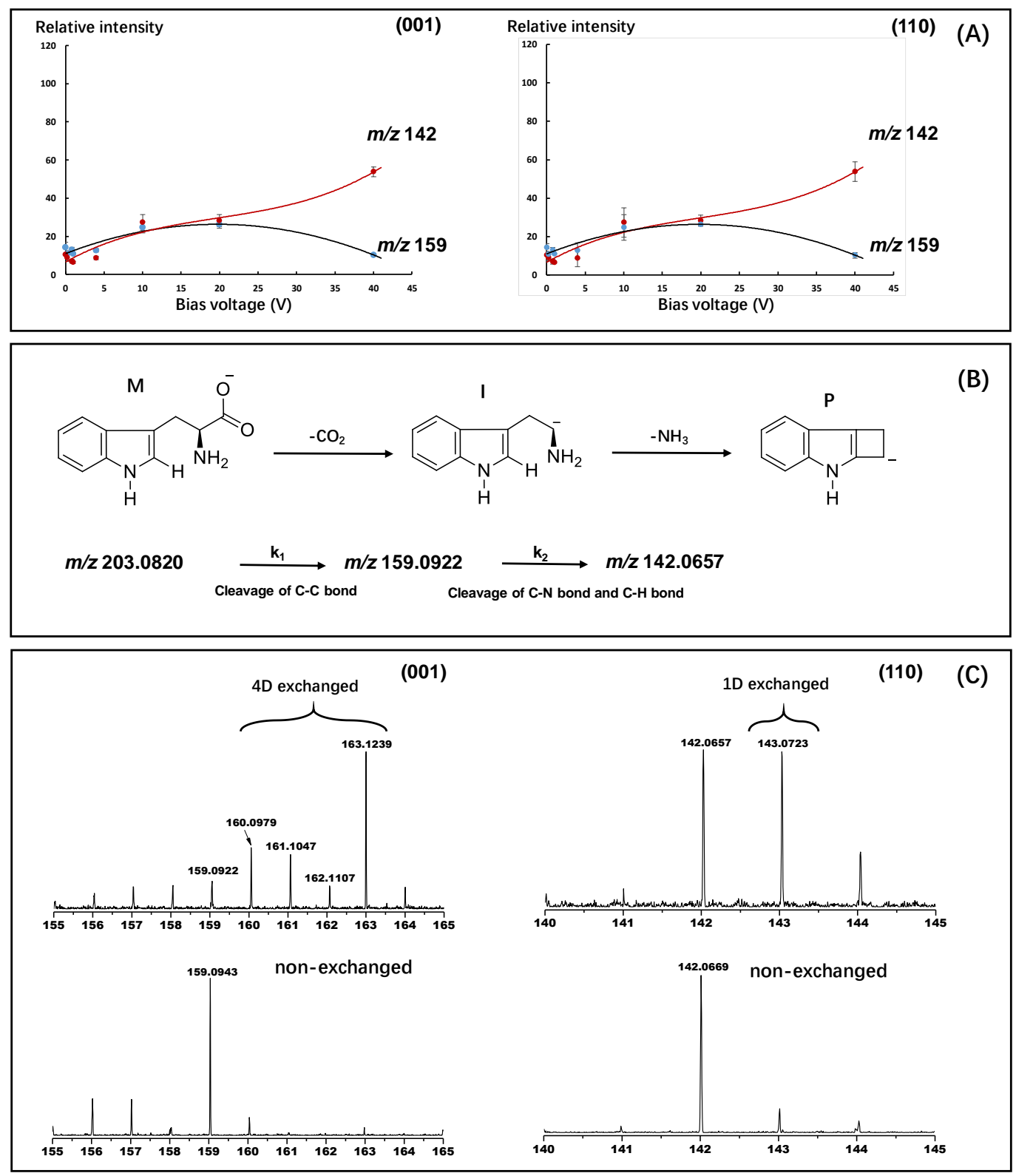

Figure 4 

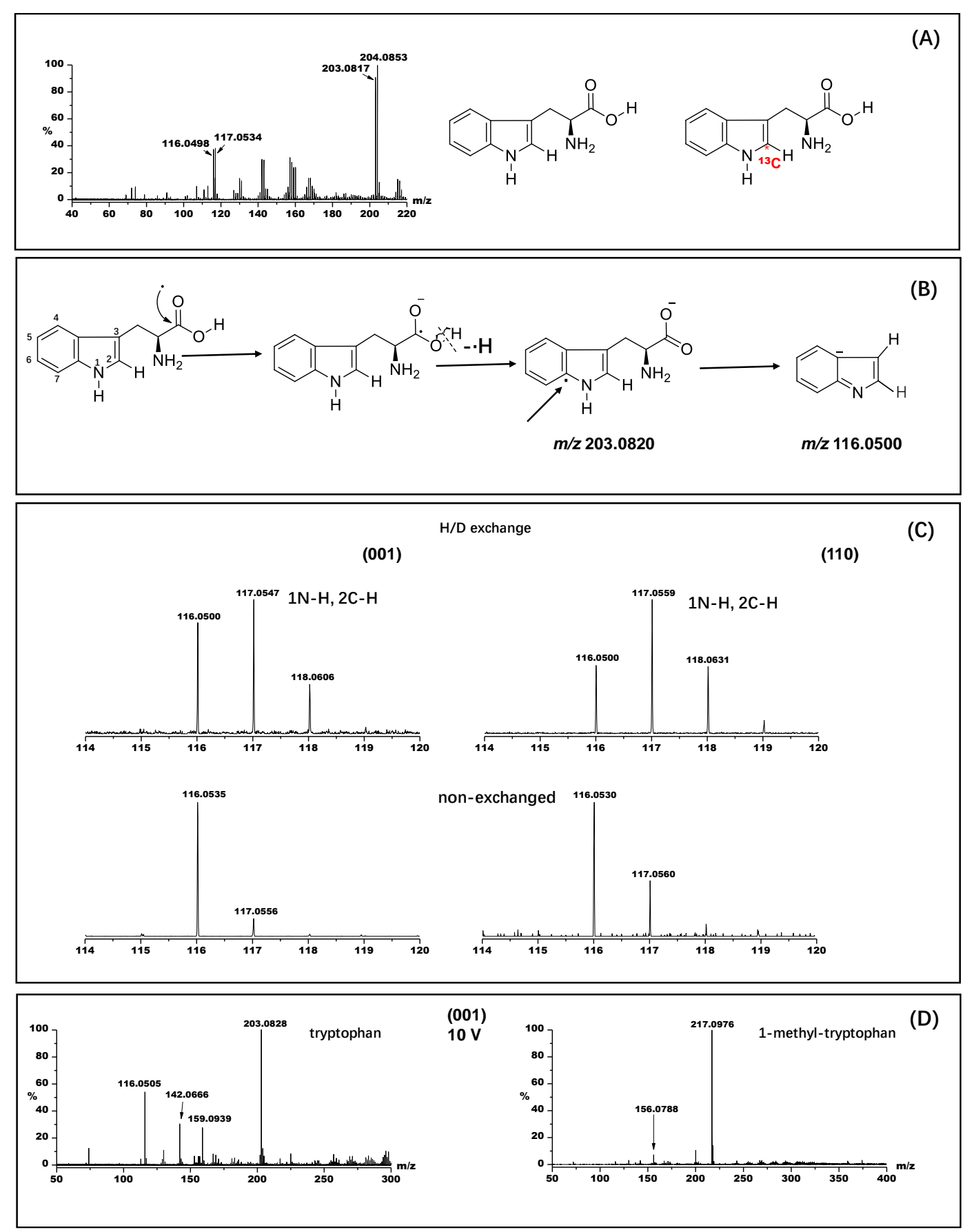

Figure 5 


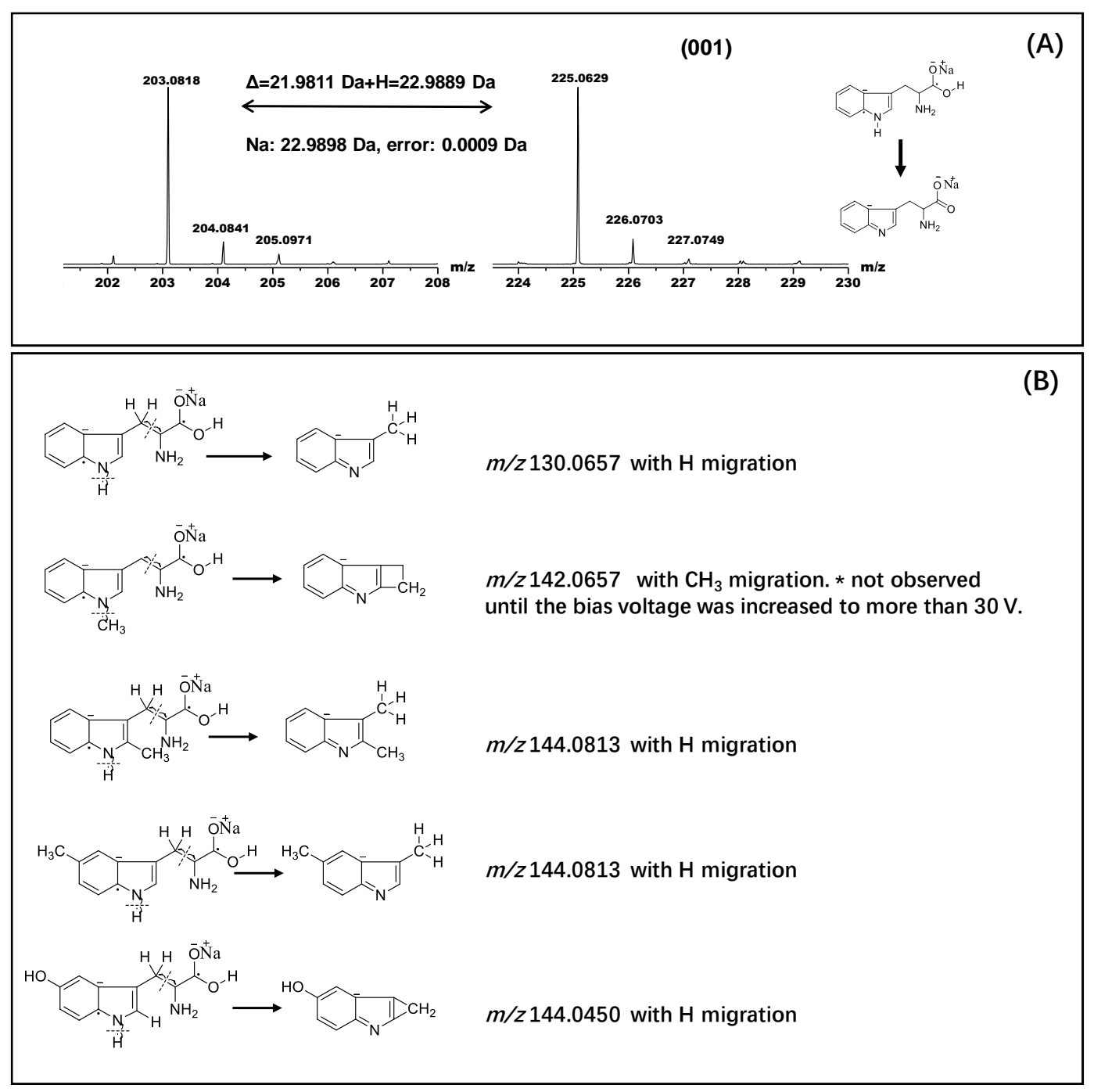

Figure 6 


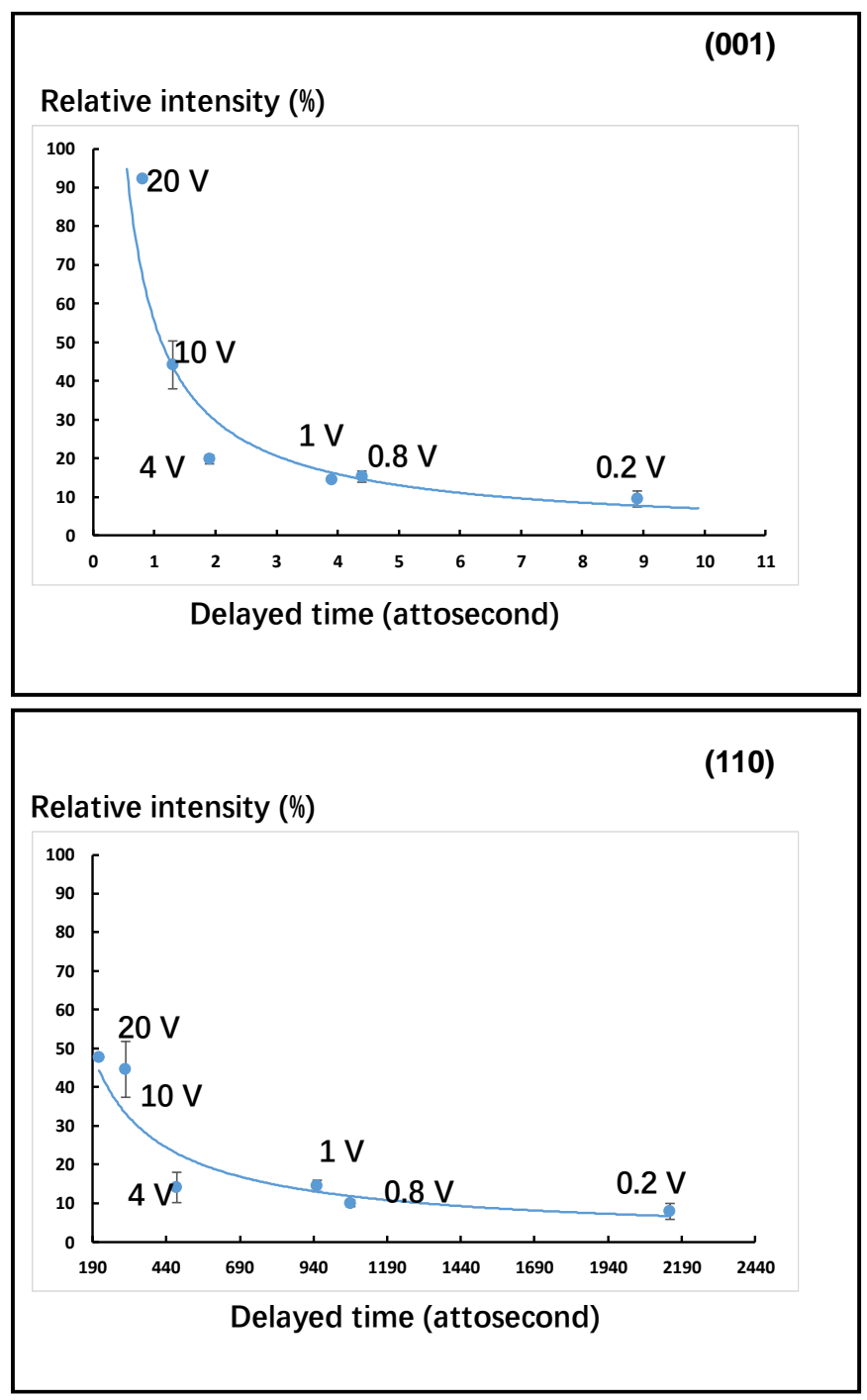

Figure 7 


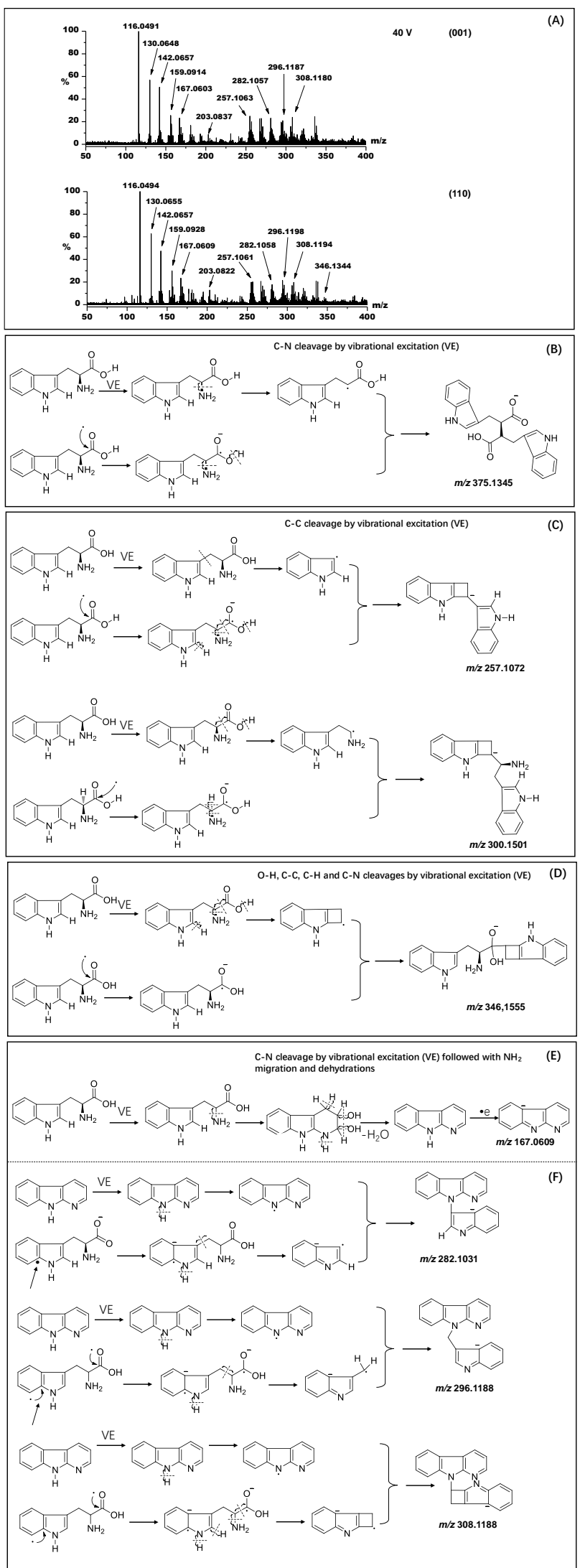

Figure 8 


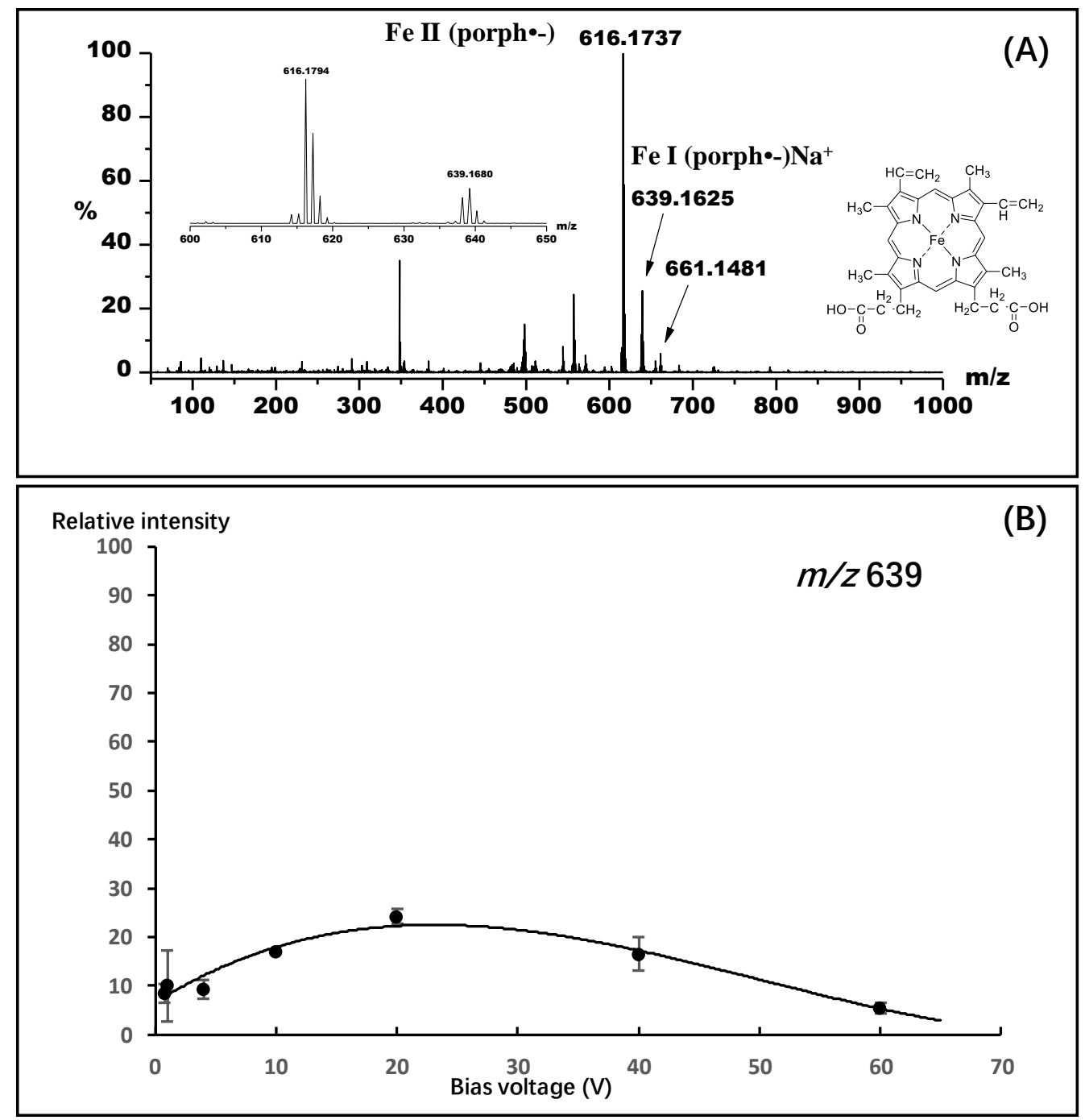

Figure 9 